\title{
Are Mathematics Faculty Ready for Common Vision?
}

\section{Marcus Jorgensen}

Note: The opinions expressed here are not necessarily those of Notices. Responses on the Notices webpage are invited.

I find A Common Vision for the Undergraduate Program in 2025 [1] a remarkable effort on the part of the various national associations with interests in college mathematics education. Tara Holm and Karen Saxe [2] made this comment:

\begin{abstract}
Change is coming, and the mathematical sciences community must come together to ensure that the change happens coherently and in a mathematically sound way. More mathematicians must become involved, working with colleagues from partner disciplines to modernize curricula and adopt evidence-based active learning strategies in mathematics classrooms. (p. 630)
\end{abstract}

I worry about colleagues who do not see a need to change or who believe in the traditional algebra for everyone.

I am writing this with a particular emphasis on general education mathematics for college freshmen and for those institutions that require college algebra for nearly all students. College algebra for freshmen has changed little in 150 years. As I look at my collection of nineteenth-century algebra textbooks, they are remarkably similar to what is taught today (with the major exception that they do not cover graphing). The similarity is either a testament to its enduring quality or to our inability to change and adapt to the times. I believe it is the latter, and change will only happen if it is supported by the faculty.

How do we know if the faculty are ready for the types of changes in Common Vision such as alternate pathways for students? Through my research and observations, I have concluded that you can tell how ready a faculty member is for change by asking four questions. These questions get to the heart of some basic tenets and beliefs that show either a willingness or reluctance to change. The

Marcus Jorgensen is associate professor of developmental mathematics at Utah Valley University. His e-mail address is jorgenma@ uvu. edu.

For permission to reprint this article, please contact: reprint-permission@ams .org.

DOI: http://dx.doi.org/10.1090/noti1441

questions are whether or not one agrees with the following statements:

- Algebra students should memorize the quadratic formula.

- Intermediate and college algebra have broad relevance in the "real world."

- Algebra, like no other subject, improves the brain's ability to think critically.

- Creating customized undergraduate pathways for students amounts to lowering standards.

\section{Memorizing the Quadratic Formula and the Mathematics Attic}

As heretical as this may seem to some, but not all, why do we insist on students memorizing the quadratic formula? Don't get me wrong; I have nothing against memorization. But if we made a prioritized list of information that students should memorize, would this be high on the list? It seems more important that they know what it is, where to find it, and how to use it. Better yet, why not use modern tools to do the quadratic formula calculations?

May I suggest that finding $i$ to the $n$th power, rationalizing denominators, long division of polynomials, or any number of similar college algebra concepts would not stand the scrutiny of developing a truly modern and relevant curriculum for nonmath majors.

I attended an interesting session at the 2012 AMATYC conference presented by a father and son team, Tom and Scott Adam-

\section{The attic analogy is an important one} son. The session title was "The Mathematics Attic." They suggested that there are a number of things that we do not use but do not want to throw away either, such as an abacus. So we put them in the mathematics attic. They went on to suggest a number of current items that could probably go into the attic. They asked the audience for other suggestions for the attic, and there was no shortage of ideas. 
The attic analogy is an important one. There are a number of interesting but outdated algebraic topics that we do not want to lose. So we could put them in the attic and bring them out for the mathematics majors to learn and appreciate. All freshmen do not need to see them. A faculty member willing to change is one who is open to consigning classics to the attic.

\section{Relevance}

This may not be a popular position with mathematics faculty, but I think that algebra in and of itself and as an end goal is not broadly relevant. By relevant I mean meaningful for a student's major, future employment, decision making in life, or citizenship in a democracy. Of course, there are algebraic skills that are important to follow-on math courses. However, when the traditional college algebra is the final destination, students are deprived of seeing how useful it can be, and they never get to see some other beautiful and relevant mathematics.

Defenders of algebra-for-all tend to cherry-pick algebraic concepts that are easy for students to see in their lives. Once, at a statewide education meeting with dozens of mathematics teachers from higher education institutions in the state, an instructor stood up and interrupted the meeting and said she was tired of everyone picking on mathematics. She asked the speaker, "How did you decide when to get up this morning and get to class on time?" She then added, "That's algebra." She explained that she uses that same example with her students and that algebra is used all the time in real life. She sat down to the loud ovation of her colleagues. I did not clap. While I suppose that example involved some low-level algebra, it seems disingenuous. A student does not simplify complex rational expressions or find the fifth root of a number as a matter of course in real life. Perhaps the most damning evidence against the relevance of algebra is the large proportion of traditional textbook word problems that are contrived and unrealistic.

\section{Algebra and Thinking Critically}

If you look for experimental evidence that learning algebra increases a student's ability to think more critically, you will find little. Yes, there is something to be learned by solving equations and problems using rules and logic. However, I can make the case that the traditional curriculum fosters almost the opposite of critical thinking. Students sit and listen to the instructor explain a concept and then get some chance to practice. Then the students are required to mimic that work on a test and try and get the one correct answer. The world, however, is often not black and white with one correct answer; it is complicated.

Secondly, word problems usually include exactly the information a student needs in the solution. Students can often memorize some type of formula, pattern, or algorithm to get the correct answer without really doing much critical thinking. If we really wanted to teach critical thinking, then we should do it intentionally and structure our teaching to encourage that type of thinking.

Some faculty believe there is something inherent about mathematics, and algebra specifically, that helps critical thinking. Faculty who believe in the inherent qualities of algebra without being able to articulate what that specifically means and provide evidence to support it are not ready for Common Vision. I believe that there is a level of numeracy that is vital to critical thinking, but the algebraheavy, traditional curriculum often leaves that type of learning to chance. Faculty who are ready for change must be able to think critically and specifically about curriculum design and student learning rather than having vague notions of learning outcomes with nothing more than anecdotal supporting evidence.

\section{Pathways and Rigor}

An alternative path that does not go through college algebra or even intermediate algebra is seen by some faculty as watering down the curriculum. These faculty believe in the sanctity of algebra and its inherent rigor and benefits. Alternate pathways for them are attempts to weaken the curriculum in an effort to appease administrators and give in to the pressure to improve retention and graduation rates.

It is an interesting assumption that freshman mathematics courses other than algebra are not as rigorous as algebra. I fail to see why that has to be the case. An academic advisor once told me that his answer to students who questioned why they had to take College Algebra was that "you have to eat your broccoli before you eat your steak." In other words, you may not like it and it may be hard to eat, but-trust me-it will be good for you. I do not accept that as justification in itself for a course requirement. Surely there are many academically rigorous and challenging freshman mathematics courses other than College Algebra that are more relevant and stimulate critical thinking. Faculty who have the broccoli mindset are not ready for curricular change.

My hope is that this article can stimulate thinking on some key issues related to faculty beliefs and support of change to the freshman mathematics curriculum.

\section{References}

[1] A Common Vision for the Undergraduate Mathematics Program in 2025: Project Overview for the White House Office of Science and Technology Policy, January 22, 2015. Retrieved from: www. maa.org/sites/default/files/pdf/common-vision/ cv_white_paper.pdf,

[2] T. Holm and K. SAXE, A Common Vision for undergraduate mathematics, Notices Amer. Math. Soc., June/July 2016. 


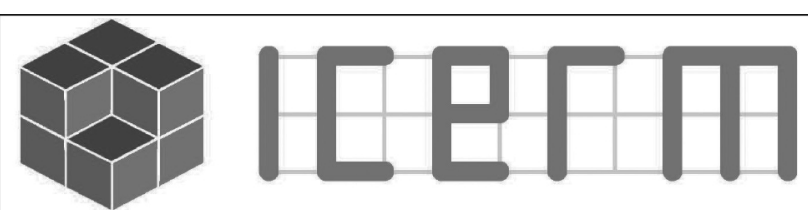

Institute for Computational and Experimental Research in Mathematics

\section{UPCOMING TOPICAL WORKSHOPS}

JANUARY 24 - 27, 2017: CURRENT DEVELOPMENTS IN MATHEMATICAL FLUID DYNAMICS: REGULARITY, INSTABILITIES, AND TURBULENCE:

The purpose of this workshop is to gather leading experts, postdoctoral scholars, and graduate students, to present exciting new developments in the field of mathematical fluid dynamics. The focus of the meeting will be placed on current research on regularity, instabilities, and the onset of turbulence in fluid flow, from a theoretical and from a computational perspective. In particular, the conference will celebrate the work of Susan Friedlander, who has been making important contributions in the field since 1970s. Organizers: P. Constantin, Princeton University; N. Pavlovic, University of Texas at Austin; V. Vicol, Princeton University.

JUNE 5 - 9, 2017: PROBABILISTIC SCIENTIFIC COMPUTING: STATISTICAL INFERENCE APPROACHES TO NUMERICAL ANALYSIS AND ALGORITHM DESIGN: There is an urgent and unmet need to formally analyze, design, develop and deploy advanced methods and algorithms that can scale in statistical and computational efficiency to the size of modern data sets and the complexity of contemporary mathematical models. The primary goal of this workshop is to introduce recent results and new directions in probabilistic scientific computing to the US research communities in statistics and machine learning, in numerical analysis, and in theoretical computer science. Organizers: P. Hennig, Max Planck Institute; G. E. Karniadakis, Brown University; M. A. Osborne, University of Oxford; H. Owhadi, Caltech;P. Perdikaris, MIT.

JULY 17 - 21, 2017: WOMEN IN DATA SCIENCE AND MATHEMATICS RESEARCH COLLABORATION WORKSHOP (WISDM): This program will bring together women at all stages of their careers, from graduate students to senior researchers, to collaborate on problems in data science. The scientific focus will be on cutting edge problems in the areas of predictive modeling, multi-scale representation and feature selection, statistical and topological learning, and related areas. Organizers: C. Domeniconi, George Mason University; E. Gasparovic, Union College; G. Heo, U. of Alberta; K. Leonard, CSU Channel Islands; R. Liu, Rutgers University; J. Mitchell, University of Wisconsin; D. Needell, UCLA, L. Ness, Rutgers University; X. Wang, Wilfrid Laurier University.

AUGUST 21 - 25, 2017: PEDESTRIAN DYNAMICS: MODELING, VALIDATION AND CALIBRATION: The complex dynamical behavior of large pedestrian crowds has long fascinated researchers from various scientific fields. With ongoing technical development, more and more data such as pedestrian trajectories and velocities have become available, leading to new questions of calibration of the mathematical models. This workshop aims to foster interdisciplinary research and to explore new research directions such as data assimilation techniques and big-data analysis. Organizers: A. Barbaro, Case Western Reserve University; J. A. Carrillo, Imperial College London; B. Piccoli, Rutgers University; A. Seyfried, Forschungszentrum Jülich; M-T. Wolfram,University of Warwick.

$\begin{array}{ll}\text { Ways to participate: } & \text { About ICERM: The Institute for } \\ \text { Propose } a \text { : } & \text { Computational and Experimental Research } \\ \text { - semester program } & \text { in Mathematics is a National Science } \\ \text { - topical workshop } & \text { Foundation Mathematics Institute at } \\ \text { - small group research program } & \text { Brown University in Providence, Rl. } \\ \text { - summer undergrad program } & \\ \text { Apply for } a \text { : } & \text { semester program or workshop } \\ \text { - postdoctoral fellowship } & \\ \text { Become an: } & \\ \text { - academic or corporate sponsor } & \end{array}$

Photo Credit

Photo of Marcus Jorgensen is courtesy of Corey Peel.

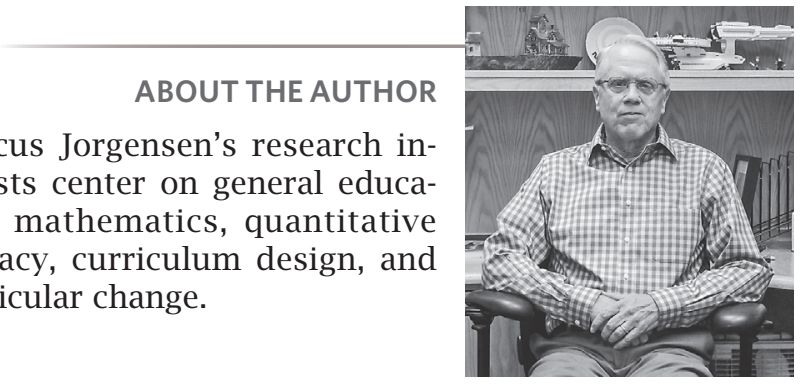

Marcus Jorgensen 